\title{
Stress, Coping Strategies and Perceived Faculty Support among Nursing Students in Alexandria
}

\author{
Fathia Khamis Kassem, Lecturer \\ Community Health Nursing, Faculty of Nursing, Alexandria University \\ Rasha Abd El Hakim Abdou, Lecturer \\ Community Health Nursing, Faculty of Nursing, Alexandria University
}

\begin{abstract}
Nursing students experience greater stress through their nursing program. This stress is undoubtedly related to the intensity and complexity of nursing program and its effects on their health and wellbeing are compounded. High perceived stress levels and lack of effective coping strategies and faculty support could be a barrier to achieve the challenges of nursing profession. Objective: Assess baccalaureate nursing students' stress level, coping strategies and perceived faculty support and identify stress related factors among them. Setting: The study was carried out at Faculty of Nursing, Alexandria University. Subjects: 400 baccalaureate nursing students. Tools: Five tools were used for data collection. The first tool was nursing students' basic data structured interview schedule to identify data related to students' personal and socio-demographic characteristics. The second tool was Student Nurse Stress Index (SNSI) to assess the nurse students stress levels. The third tool was Physio- Psycho- Social Response Scale (PPSRS) to describe students' responses to stress during their nursing program. The fourth tool was The Coping Behavior Inventory (CBI) to measure the coping strategies used by nursing students during stress exposure. Finally, the fifth tool was Perceived Faculty Support Scale (PFS) to measure the students' perception of faculty support in their nursing program. Results: Findings of the present study revealed that the majority (91.5\%) of the students were stressed and the most common coping strategy used was problem solving (65.3\%), while only 3.8\% of them perceived low faculty support. Students' stress was related to many personal and extracurricular factors. Conclusion: The study concluded that baccalaureate nursing students experience high levels of stress during their nursing education which affects not only academic performance, but also all aspects of students' health. Recommendations: There should be a collaborative effort among academic staff members to remove unnecessary stressors and provide a supportive learning environment. Regular meeting should be held between students and academic staff members to discuss the possible stressful situations that might happen.
\end{abstract}

Keywords: Student nurses' stress, coping strategy, faculty support.

\section{Introduction}

A critical, long term and global nursing shortage has increased the significance of preparing nursing students in sufficient numbers to improve the quality of health care. At the same time, a more complex, rapidly changing, and acutely ill health care environment requires nursing graduates to possess higher levels of knowledge and improve clinical judgment. Although, nursing programs faculty have responded appropriately by developing more rigorous and challenging curricula, a more competitive, stressful and high stakes learning environment has evolved ${ }^{(1)}$.

Nursing students experience greater stress through their nursing program. This stress is undoubtedly related to the intensity and complexity of nursing programs, 
including academic, clinical and personal stressors $^{(2)}$.

Academic stress includes continuous examinations, research papers and other assignments and longer study hours associated with lack of free times as nursing students have a large amount of preparatory work before their clinical assignment ${ }^{(3)}$.

In clinical rotations, students must exhibit a high level of responsibility and accountability in dealing with patients. Students often perform procedures that can cause serious harm to their patients and fear making a mistake along with insecurity about one's clinical competence and perceived lack of practical skills. Time management can be a pressure as they have many tasks that must be accomplished in a short period of time together with continuous contact with instructors for evaluation of performance. Additionally, the atmosphere on the nursing unit may be unfriendly or aloof, which adds to the student's sense of self-doubt and insecurity $^{(4,5)}$.

In addition, nursing students experience personal stress such as adaptation to new environment, financial worries, concerns about career direction and problems related to family matters ${ }^{(6)}$.

However, extensive and compelling evidence shown that high stress levels in nursing students may affect memory, concentration , and problem solving ability, which may lead to decreased learning, coping, academic performance, and retention $^{(1)}$. Moreover, high stress levels may affect all aspects of students' health such as the development of hypertension, heart diseases, and nutritional disorders ${ }^{(7)}$.

Although students cannot avoid stressors, their ability to cope is important in achieving success in their academic and social environments. The effects of stress on health depend on the adequacy of coping strategies, which play a vital part in the stress adjustment process $^{(7)}$.
Educators often emphasize the acquisition of knowledge, so they often neglect the emotional feelings of students during teaching process, which can lead to emotional stress and learning problems. In addition, students may experience increasingly intense feelings of nervousness, worry, frustration, abasement and depression. If faculties, educators do not provide an appropriate timely support to over stressed students, the instability of these emotions can easily initiate unusual behaviors, which then affects the learning achievements and adjustment ability of the students ${ }^{(8)}$.

Faculty members as gatekeepers to the profession are in a very influential position in regards to the future career of their students. Increased faculty support by way of psychological support as well as provision of functional support services will be beneficial in aiding students' overall success ${ }^{(5,7)}$.

Nursing students experience many stressors and its effects on their health and wellbeing are compounded. So, health promotion efforts are needed to increase the options available for nursing students to exercise more control over their own health, environment and make choices conducive to optimal health $^{(9)}$.

Therefore, in order to maintain a healthy body and mind and to develop normal operational functions, the community health nurse should manage students' stress with more health promotion strategies such as stress management and healthy coping skills with adequate social support which can mediate the effects of the stress experience. Health promotion efforts are vital to furnish comprehensive care for nursing students, as it is not only beneficial in routine health care but can help nursing students assimilate positive life style choices and reach optimal well being ${ }^{(10,11)}$.

Evidence related to the causes and effects of stress of Egyptian baccalaureate nursing students and their self initiated 
stress coping strategies in relation to their perception of faculty support remains limited. It was anticipated that this study would highlight the problem of stress among nursing students, which in turn help the nursing educators to identify the common stressors experienced by the students in their program as to what support and guidance are needed for students to relief stress, thus promoting a positive academic and clinical experiences.

\section{Aims of the Study}

\section{The aims of the study are to:}

- Assess the nursing students stress level, coping strategies and perceived faculty support in Faculty of Nursing, Alexandria University.

- Determine the nursing students stress related factors in Faculty of Nursing, Alexandria University.

\section{Research Questions:}

- What is the level of stress experienced by the nursing students in the Faculty of Nursing, Alexandria University?

- What are the coping strategies used by the nursing students to adapt to perceived stressors in the Faculty of Nursing, Alexandria University?

- What is the level of faculty support perceived by the nursing students in the Faculty of Nursing, Alexandria University?

- What are the nursing students stress related factors in Faculty of Nursing, Alexandria University?

\section{Materials and Method}

\section{Materials}

Design: The descriptive design was adopted to carry out this study.
Setting: The study was conducted in the Faculty of Nursing, Alexandria University.

Subjects: By using the equal allocation method, a convenient sample of 100 undergraduate baccalaureate nursing students was selected from each grade (50 males, 50 females) during the academic year 2013-2014. They accounted for 400 undergraduate baccalaureate nursing students.

Tools: In order to collect the necessary data for the study, the following tools were used:

Tool I: Nursing students' basic data structured interview schedule

This was developed by the researchers to collect the necessary data from the students. It included the following parts:

First part: Socio demographic data about the students and their parents such as age, birth order, level of education of student' parents', occupation, marital status and social level which was assessed using El-Gilany A et al Scale ${ }^{(12)}$.

Second part: Physical health status data: It included data about the health status of the students and presence of health problems.

Third part: Students social status: It included data about leisure time activities and extracurricular activities and work.

Forth part: Students' perspectives of nursing as profession such as reason for choosing nursing as a career, and the degree of satisfaction about nursing.

\section{Tool II: Student Nurse Stress Index} $\underline{(\text { SNSI) }}$

It is a self reported instrument developed by Jones and Johanson in 1999 to measure student nurses stress levels ${ }^{(13)}$. The SNSI consisted of 22 items clustered into four domains: academic workload, clinical concerns, personal problems, and interface worries. All items used a likert scale ranging from 1 meaning not stressful to 5 meaning extremely stressful. The reliability 
coefficient of the entire scale by Cronbach's alpha was 0.83 .

\section{Tool III: Physio-Psycho-Social Response Scale (PPSRS)}

It was developed by Sheu et al (2002), which is used to describe nursing students' responses to stress during their nursing program $^{(14)}$. The PPSRS consists of 21 items rated on a five-point likert-type scale. The 21 items are divided into three subscales: physical symptoms, emotional symptoms, and social-behavioral symptoms. Higher scores indicate the presence of more and serious symptoms reported and poorer physio-psycho-social health status. The Cronbach's alpha for the entire scale was 0.94 and ranged from 0.91 to 0.94 for the subscales.

\section{Tool IV: The Coping Behavior Inventory $\underline{\text { (CBI) }}$}

It was developed by Sheu et al in 2002 to identify nursing students' coping strategies $^{(14)}$. It consists of 19 items, and uses a 5 point likert scale. It divided into four coping strategies including: avoidance, problem solving, stay optimistic, and transference. A higher score of each factor indicates more frequent use and greater effectiveness of certain type of coping strategy. The reliability coefficient of the entire scale by Cronbach's alpha was 0.80 .

\section{Tool V: Perceived Faculty Support Scale $\underline{\text { (PFS) }}$}

It was developed by Shelton in 2003 as a mean for measuring students' perceptions of faculty support received in their nursing program $^{(15)}$. It inquires 24 items, subdivided into two subscales to measure faculty psychological and functional support. Each item was scored using a 5 point likert scale that ranged from 1 meaning strongly disagree to 5 meaning strongly agree. The reliability coefficient of the entire scale by Cronbach's alpha was 0.96 .

\section{Method}

- Approvals of the responsible authorities were obtained from the Faculty of Nursing after explanation of the purpose of the study.

- After reviewing the recent relevant literature, tool (I) was developed by the researchers. It was validated by juries of (5) experts in the field of Community Health Nursing. Their suggestions and recommendations were taken into consideration.

- An English version of tool II, III, IV, $\mathrm{V}$ was used.

- A pilot study was carried out on 40 nursing students in order to ascertain the relevance, clarity and applicability of the tools, test wording of the questions and estimate the time required for the interview. Based on the obtained results, the necessary modifications were done.

- Data was collected by the researchers during the academic year 2013-2014 over a period of 3 months (from March 2014 to May 2014).

\section{Ethical considerations:}

- Informed written consents were obtained from the students after brief explanation of the purpose and nature of the research.

- The anonymity and confidentiality of responses, voluntary participation and right to refuse to participate in the study were emphasized to students.

\section{Statistical Analysis}

- The collected data were coded and analyzed using PC with the statistical package for social sciences (SPSS version 20) and 
tabulated. Frequencies and percentages were calculated.

- The level of significance selected for this study was $\mathrm{P}$ equal to or less than 0.05 . It was used as the cut off value for statistical significance.

\section{Results}

Table (1) shows that the students' age ranged from 18 to 24 years with a mean of $20.53 \pm 1.48$ years. The majority $(94.7 \%)$ of them were single, $58.7 \%$ of the students were urban dwellers and $67.7 \%$ of them were living with their families while studying. Additionally, $23 \%$ of the students were working beside their education and 25.75 of them had chronic health problems.

Table (2) reveals that only $14.5 \%$ of the students obtained (C-) in the last semester, while only $2 \%$ of them experienced previous academic failure. Furthermore, the majority $(93.2 \%)$ of the students reported regular attendance to the faculty and $44.5 \%$ of them studied for less than 3 hours per day while $21.5 \%$ of them slept for more than 7 hours every day. It was noted that only $17 \%$ of the students joined the nursing faculty by their own choice and $12.5 \%$ of them were dissatisfied with nursing as a career because of poor nursing image as stated by $40 \%$ of them.

Table (3) portrays that the majority $(95 \%)$ of the students' parents were satisfied with joining the carrier of nursing. Less than one fourth $(20.7 \%)$ of the students were ranked as low social level. Moreover, $15 \%$ of the students' fathers and $21.3 \%$ of their mothers had university education or more.

Table (4) Less than three quarters $(71.5 \%)$ of the students had high stress level, and only $8.5 \%$ of them had low stress. Furthermore, the majority $(86.8 \%)$ of the students had high academic stress, while less than two thirds of them had high clinical concerns and personal problems $(62.8 \%, 65.3 \%$ respectively). On the other hand, only $16.8 \%$ of the students had low interface worries.
Figure (1) reveals that less than three quarters of first/second and seventh/eighth semester students experienced high stress level (74\%, 72\% respectively), followed by those enrolled in third/fourth and fifth/sixth semester $(66 \%, 42 \%$ respectively). On the other hand, none of the first/second semester students and a minority of those at third/fourth, seventh/eighth semester (5\%, $9 \%$ respectively) compared to $20 \%$ of the fifth/ sixth semester students expressed low stress level.

Figure (2) reveals that critical care nursing was the most stressful course experienced by the majority of nursing students $(90.2 \%)$, followed by medical surgical nursing (87.4\%). On the other hand, gerontological nursing was the least stressful course as stated by $17.5 \%$ of the students.

Table (5) shows that the lowest percentages of the students had severe physical, psychological and social responses to stress $(3.6 \%, 4 \%$, and $6.5 \%$ respectively). The most common response to stress was the psychological response with a mean of $1.82 \pm 0.67$.

Table (6) presents the students coping strategies to stress. The most common used coping strategies was problem solving as reported by $65.3 \%$ of the students, followed by transference $(52.8 \%)$, avoidance $(16.8 \%)$, and finally stay optimistic as mentioned by $7 \%$ of the students.

Table (7) portrays the students ' perception of faculty support. It was found that a minority $(3.7 \%)$ of the students had a low sense of faculty support compared to $14.8 \%$ of them had a sense of high faculty support. The highest percentages of the students perceived moderate functional and psychological faculty support (78.7\%, $69.5 \%$ respectively).

Table (8) shows the correlation analysis between students' stress, coping strategies and perceived faculty support. A significant negative correlation between the students' stress and perceived faculty support was 
found. Additionally, a significant negative correlation was found between students' stress and problem solving coping strategy which indicates that the students who rely on problem solving as a coping strategy tend to have less perceived stressors than those students who utilize other coping strategies.

Table (9) illustrates predictors of stress among the nursing students. The table reveals that ten variables were found to be predictors of students' stress namely academic semester $(\mathrm{P}=0.024)$, reason for joining the faculty $(\mathrm{P}=0.026)$, previous academic failure $(\mathrm{P}=0.029)$, last semester GPA $(\mathrm{P}=0.006)$, work beside education $(\mathrm{P}=0.042)$, number of studying hours $(\mathrm{P}=0.029)$, number of sleeping hours $(\mathrm{P}=0.052)$, practicing extracurricular activities $\quad(\mathrm{P}=0.046)$, satisfaction with nursing as a career $(\mathrm{P}=0.020)$ and perceived faculty support $(\mathrm{P}=0.039)$.

\section{Discussion}

It is well recognized that nursing is a stressful occupation. However, the problem of stress does not begin when the nurse qualifies, but is evident during nurse education and training ${ }^{(8)}$. The same was acknowledged by Gurbinder $\mathrm{K}$ et al $2011^{(16)}$, Singh $\mathrm{C}$ et al $2011^{(17)}$ and Mohamed B et al 2012(18) who stated that stress is linked to the nursing profession and nursing students experience more stress than do students in other health care disciplines. This is in agreement with the results of the present study findings which indicated that the majority $(91.5 \%)$ of the nursing students were under stress and $71.5 \%$ of them were highly stressed. This may be attributed to the complexity and intensity of the nursing program.

Nurses were reportedly encountering endless stress while pursuing their undergraduate program. Several studies suggested that there are many sources of stress during undergraduate nursing education and training. The most common sources of stress identified by students were those related to academic demands such as assignments, examinations, as well as amount of class work $^{(15,16,19,20)}$.This is in line with the findings of the present study which indicated that the majority of the students expressed high academic load. This result can be explained by the fact that the majority of students spend most of their school years in passive learning environments that do not foster the development of synthesizing, problem solving and creative thinking abilities which is highly needed in higher education especially in nursing programs. So, the students should be changed into active learners instead of being passive receivers which may lead to more stress experienced by the students in the journey of nursing education.

Clinical practice is an essential part of nursing education as it provides nursing students the opportunities to apply knowledge as well as developing their psychomotor skills ${ }^{(2,16)}$. The clinical practice can be source of the students' stress because of the complexity and acuity of patient care, interactions with members of the multidisciplinary team and the process of balancing day to day clinical demands with the educational demands simultaneously ${ }^{(4,7,8,21)}$. These findings come in accordance with the results of the present study which found that only less than one tenth of the nursing students expressed low clinical concerns.

Student nurses' stress is also related to environmental and personal factors that a majority of students are destined to experience such as financial concerns, lack of free times and problems related to family obligations which have more significance on influencing a students' level of retention and academic achievement ${ }^{(7,16)}$. These issues are common among the students generally, but they are more pronounced of the nursing students because of the increased courses demands; as it is a vocational course, which by definition limits career options, and because those 
demands affects significant number of students where the changes have to be incorporated into home and family commitments. This was reflected in the present study findings as the majority of the students complained of personal problems and interface worries. Consistent findings were reported by Gibbon $\mathrm{C}$ et al $2008^{(8)}$, Misra R et al 2011 ${ }^{(20)}$, Kit C $2006^{(22)}$, and Burnard P et al $2007^{(23)}$.

As regard education, stress can consume students to the point that impair their wellbeing that could result in deleterious psycho-physio-social symptoms such as drug dependence, alcoholism, eating disorders, sleep disorders and even risk taking behaviors ${ }^{(1,14,24,25)}$. Thus, the undergraduate years for student nurses is considered as one of the most sensitive period in their lifespan since learning during these years may be compromised due to stress reactions produced. The findings of the present study revealed that the highest percentages of the students showed mild psychological and physical response to stress throughout their education. It may be as a result of their ongoing experiences of academic, clinical and personal stressors, which in turn subjected them to many physical, emotional and psychological ailments. Similar findings were reported by Kit C 2006 ${ }^{(22)}$, Jabien L 2013 ${ }^{(24)}$, and Burnard P et al $2008^{(26)}$ who reported that nursing students who experienced increasing levels of stress, were more likely to report psycho- physical symptoms.

Student nurses face a lot of stressors which bring advantages and disadvantages to them. It depends on how nursing students are going to look upon them and take over them. Coping with stress means confronting or escaping the problem and taking steps to prevent it, solving the problem or mentally distancing on self from it ${ }^{(27)}$. It is apparent from the present study findings that the most commonly used coping strategy was problem solving $(65.3 \%)$, with a negative significant correlation with students' stress. This may be attributed to the nature of the nursing program, that throughout various learning opportunities, the nursing students develop better critical thinking abilities and problem solving skills. Also, they gained a better degree of knowledge and more clinical experiences and can therefore make use of that knowledge and experience to identify and handle stressors faced. In agreement, Shaban I et al $2012^{(7)}$, Singh C et al $2011^{(17)}$, Kit C $2006^{(22)}$ who found that problem solving is the most effective coping strategy used by nursing students to overcome faced stress.

In a profession that is labeled as stressful one, the nursing students can not completely eliminate stress in their education/ training process, but can control how much it affects. Stress can be managed through use of healthy coping strategies and through effective social support which can originate from not only family and friends but also from faculty members. Social support influences the students' perception of stressors and mediates its effects; creating an atmosphere more conducive to academic achievement ${ }^{(17,19)}$.

Nursing students' academic achievement depends not only on the quality of the curriculum and classroom instructions, but also on the effectiveness of key out of class services that the faculty staff created to support nursing students' success and promote their wellbeing. In agreement, the results of the present study showed that perceived faculty support was a predictor of students' stress with a negative significant correlation between them. This comes in line with the results of Jensen A $2007^{(19)}$, Latric D $2008^{(28)}$ and El Sayed T et al $2013^{(29)}$ who found that the lower the faculty support, the higher the stress level experienced by the students.

Several studies indicated that senior students' nurses present lower levels of stress compared to junior students ${ }^{(4,16)}$. In junior students, the imbalance in the perceived and actual complexity of the nursing education as they were novice to nursing education. Additionally, the 
academic expectations in college can be abrupt change from those in the secondary schools causing the highest percentages of them to be stressed as in the present study finding where all the first year students were stressed. As the students get into higher levels, they were able to adapt and adjust to the academic and clinical requirements of the program. Moreover, they have already acquired and gained mastery in nursing skills necessary in the clinical experiences and develop more or less effective and efficient ways in dealing with different stressors. This come in line with the present study findings as stress was less encountered among senior students except seventh/eighth semester students, who will have to deal with more decisions about career commitments, and plan for financial security and family development, which put them into more stressors. Similar findings were reported by Gibbon $\mathrm{C}$ et al $2008^{(8)}$, Jabien L $2013^{(24)}$, Amr M et al $2011^{(30)}$, and Sharma N et al $2011^{(31)}$.

Moreover, the present study reveals that critical care nursing and medical surgical nursing were the most stressful courses experienced by the majority of nursing students. This may be attributed to the nature of these courses which entail facing many stressors such as dealing with emergency life and death situations, and responding accurately and fast to any rapid change in a patient's condition. In agreement, Mohamed B et al 2012 $2^{(18)}$, Kit C $2006^{(22)}$ who found that the majority of nursing students rated critical care nursing and medical surgical nursing as the most stressful courses.

Furthermore, the present study findings revealed that stress was less encountered among those students who joined the faculty by their own choice just because they like nursing. A possible explanation might be that interest in nursing is characterized by more satisfaction with the education environment. However, disappointment may occur because of misconceptions about what the nursing role involves. Students may have chosen a nursing career because of their aspiration to help people but often they are not prepared to deal with the complexity of the world of nursing. This finding is similar to that of Shaban I etal $2012^{(7)}$ and El Gilany A et al $2008^{(32)}$ who found that satisfaction with nursing and interest in nursing act as protective factor against students' stress.

Stress in nursing students arises from a combination of personal, academic and extracurricular factors rather than from the education program itself. The finding of the present study portrayed that several factors were associated with students' stress such as last semester GPA, previous academic failure, number of studying hours and sleeping hours and practicing extracurricular activities. Consistent findings were reported by Walton R $2002^{(4)}$, Shaban I et al 2012(7), Burnard P et al $2008^{(26)}$, and Amr M et al $2011^{(30)}$.

\section{Conclusion}

The findings of the present study revealed that nursing students exposed to multiple stressors during their nursing education and training and its effects on their health and wellbeing are compounded. Various factors contribute to the emergence and development of the problem of nursing students' stress including academic load, clinical concerns and personal problems. Accordingly, if intervention is to be carried out, it has to cover all areas simultaneously through an emphasis on the health promotion strategies such as stress management and effective coping skills with adequate faculty support.

\section{Recommendations}

- There should be a collaborative effort among academic staff members to remove unnecessary stressors and provide a supportive learning environment and create positive attitudes toward students. 
- All personnel involved with teaching nursing students including clinicians need to be adequately prepared to deal with students and to be aware of their impact on students.

- The nursing curriculum should be proactive in equipping student nurses with effective stress management and coping strategies, which can be called upon in their future nursing career.

- Regular meeting should be held between students and academic staff members to facilitate expression of feelings and discuss the possible stressful situations that might happen.
- Ensure the effectiveness of a range of support services for students throughout the nursing program which offer appropriate academic assistance and guidance.

- Efforts should be made to identify at risk students as early as possible. These students should be referred to student support services for tutoring, counseling or psychological aids. 
Table (1): Distribution of the nursing students according to their socio demographic characteristics.

\begin{tabular}{|c|c|c|}
\hline \multirow[t]{2}{*}{ Students characteristics } & \multicolumn{2}{|c|}{$\begin{array}{c}\text { Total } \\
\mathrm{N}=400\end{array}$} \\
\hline & No & $\%$ \\
\hline \multicolumn{3}{|l|}{ Age } \\
\hline - 18- years & 153 & 38.3 \\
\hline - 20- years & 137 & 34.2 \\
\hline$-22-24$ years & 110 & 27.5 \\
\hline $\mathrm{X} \pm \mathrm{SD}$ & \multicolumn{2}{|c|}{$20.53 \pm 1.48$} \\
\hline \multicolumn{3}{|l|}{ Birth order } \\
\hline - First & 87 & 21.7 \\
\hline - Second & 116 & 29.0 \\
\hline - Third or more & 197 & 49.3 \\
\hline \multicolumn{3}{|l|}{ Marital status } \\
\hline - Single (not married) & 379 & 94.7 \\
\hline - Married & 21 & 5.3 \\
\hline \multicolumn{3}{|l|}{ Family residence } \\
\hline - Urban & 235 & 58.7 \\
\hline - Rural & 165 & 41.3 \\
\hline \multicolumn{3}{|c|}{ Student residence during study } \\
\hline - With the family & 271 & 67.7 \\
\hline - Away from the family & 129 & 32.3 \\
\hline \multicolumn{3}{|l|}{ Work beside education } \\
\hline - Yes & 92 & 23.0 \\
\hline - No & 308 & 77.0 \\
\hline \multicolumn{3}{|c|}{ Presence of health problems } \\
\hline - Yes & 103 & 25.75 \\
\hline$-\mathrm{No}$ & 297 & 74.25 \\
\hline \multicolumn{3}{|c|}{ Practicing extra curricula activities } \\
\hline - Yes & 92 & 23.0 \\
\hline - No & 308 & 77.0 \\
\hline
\end{tabular}


Table (2): Distribution of the nursing students according to their academic performance and satisfaction with nursing as a profession.

\begin{tabular}{|c|c|c|}
\hline \multirow[t]{2}{*}{ Items } & \multicolumn{2}{|c|}{$\begin{array}{c}\text { Total } \\
\mathrm{N}=400\end{array}$} \\
\hline & No & $\%$ \\
\hline \multicolumn{3}{|l|}{ Last semester GPA } \\
\hline - Excellent (A, A-, B+) & 83 & 20.8 \\
\hline - Very $\operatorname{good}(\mathrm{B}, \mathrm{B}+)$ & 120 & 30.0 \\
\hline$-\operatorname{Good}(\mathrm{C}+, \mathrm{C})$ & 139 & 34.7 \\
\hline - Satisfactory (C-) & 58 & 14.5 \\
\hline \multicolumn{3}{|l|}{ Previous academic failure } \\
\hline - Yes & 8 & 2.0 \\
\hline$-\mathrm{No}$ & 392 & 98.0 \\
\hline \multicolumn{3}{|l|}{ Regular attendance } \\
\hline - Yes & 373 & 93.2 \\
\hline - No & 27 & 6.8 \\
\hline \multicolumn{3}{|l|}{ Studying hours per day } \\
\hline - 1 - hour & 178 & 44.5 \\
\hline - 3- hours & 114 & 28.5 \\
\hline$-5+$ hours & 108 & 27.0 \\
\hline $\mathrm{X} \pm \mathrm{SD}$ & \multicolumn{2}{|c|}{$3.86 \pm 1.726$} \\
\hline \multicolumn{3}{|l|}{ Sleeping hours per day } \\
\hline - 3- hours & 187 & 46.7 \\
\hline - 5- hours & 127 & 31.8 \\
\hline$-7+$ hours & 86 & 21.5 \\
\hline $\mathrm{X} \pm \mathrm{SD}$ & \multicolumn{2}{|c|}{$6.76 \pm 1.427$} \\
\hline \multicolumn{3}{|l|}{ Reasons for choosing nursing as a career** } \\
\hline - Like nursing (own choice) & 68 & 17.0 \\
\hline - Job opportunity/ security & 164 & 41.0 \\
\hline - Chance for travel abroad & 155 & 38.8 \\
\hline - Secondary school grades & 179 & 44.8 \\
\hline - Family pressure & 124 & 31.0 \\
\hline \multicolumn{3}{|l|}{ Students' satisfaction about nursing as a career } \\
\hline - Satisfied & 350 & 87.5 \\
\hline - Dissatisfied & 50 & 12.5 \\
\hline Reasons for dissatisfaction about nursing** & \multicolumn{2}{|c|}{$\mathrm{N}=\mathbf{5 0}$} \\
\hline - Poor nursing image & 20 & 40.0 \\
\hline - Lack of interest in nursing study & 16 & 32.0 \\
\hline - Overburden of the nursing work & 14 & 28.0 \\
\hline
\end{tabular}

**Multiple answers 
Table (3): The distribution of the nursing students according to their families' characteristics.

\begin{tabular}{|c|c|c|}
\hline \multirow[t]{2}{*}{ Students' families characteristics } & \multicolumn{2}{|c|}{$\begin{array}{c}\text { Total } \\
\text { N=400 }\end{array}$} \\
\hline & No & $\%$ \\
\hline \multicolumn{3}{|l|}{ Father education } \\
\hline - Illiterate/ read \& write & 118 & 29.5 \\
\hline - Basic education & 156 & 39.0 \\
\hline - Secondary education & 66 & 16.5 \\
\hline - University education & 60 & 15.0 \\
\hline \multicolumn{3}{|l|}{ Father occupation } \\
\hline - Working & 299 & 74.8 \\
\hline - Not working & 75 & 18.7 \\
\hline - Dead & 26 & 6.5 \\
\hline \multicolumn{3}{|l|}{ Mother education } \\
\hline - Illiterate/ read \& write & 72 & 18.0 \\
\hline - Basic education & 139 & 34.7 \\
\hline - Secondary education & 104 & 26.0 \\
\hline - University education & 85 & 21.3 \\
\hline \multicolumn{3}{|l|}{ Mother occupation } \\
\hline - Working & 92 & 23.0 \\
\hline - Not working & 293 & 73.3 \\
\hline - Dead & 15 & 3.7 \\
\hline \multicolumn{3}{|l|}{ Parents' marital status } \\
\hline - Married & 375 & 93.8 \\
\hline - Not married (divorced, widowed) & 25 & 6.2 \\
\hline \multicolumn{3}{|l|}{ Family's social level } \\
\hline - Low & 83 & 20.7 \\
\hline - Middle & 279 & 69.8 \\
\hline - High & 38 & 9.5 \\
\hline \multicolumn{3}{|c|}{ Students' families satisfaction about nursing as a career } \\
\hline - Satisfied & 380 & 95.0 \\
\hline - Dissatisfied & 20 & 5.0 \\
\hline
\end{tabular}


Table (4): Distribution of the nursing students according to their stress level and related factors.

\begin{tabular}{||c|c|c|c|c|c|c|c||}
\hline \multirow{2}{*}{ Students' stress } & \multicolumn{6}{|c|}{ Level of Stress } & SNSI \\
\cline { 2 - 8 } & \multicolumn{2}{|c|}{ Low } & \multicolumn{2}{c|}{ Moderate } & \multicolumn{2}{c|}{ High } & Mean score \\
\cline { 2 - 8 } & No & $\%$ & No & $\%$ & No & $\%$ & X \pm SD \\
\hline - Total SNSI score & 34 & 8.5 & 80 & 20.0 & 286 & 71.5 & $2.63 \pm 0.63$ \\
\hline - Academic load & 7 & 1.7 & 46 & 11.5 & 347 & 86.8 & $2.85 \pm 0.40$ \\
\hline - Clinical concerns & 37 & 9.3 & 112 & 28.0 & 251 & 62.8 & $2.62 \pm 0.53$ \\
\hline - Personal problems & 10 & 2.5 & 129 & 32.3 & 261 & 65.3 & $2.53 \pm 0.65$ \\
\hline - Interface worries & 67 & 16.8 & 216 & 54.0 & 117 & 29.3 & $2.12 \pm 0.66$ \\
\hline \hline
\end{tabular}

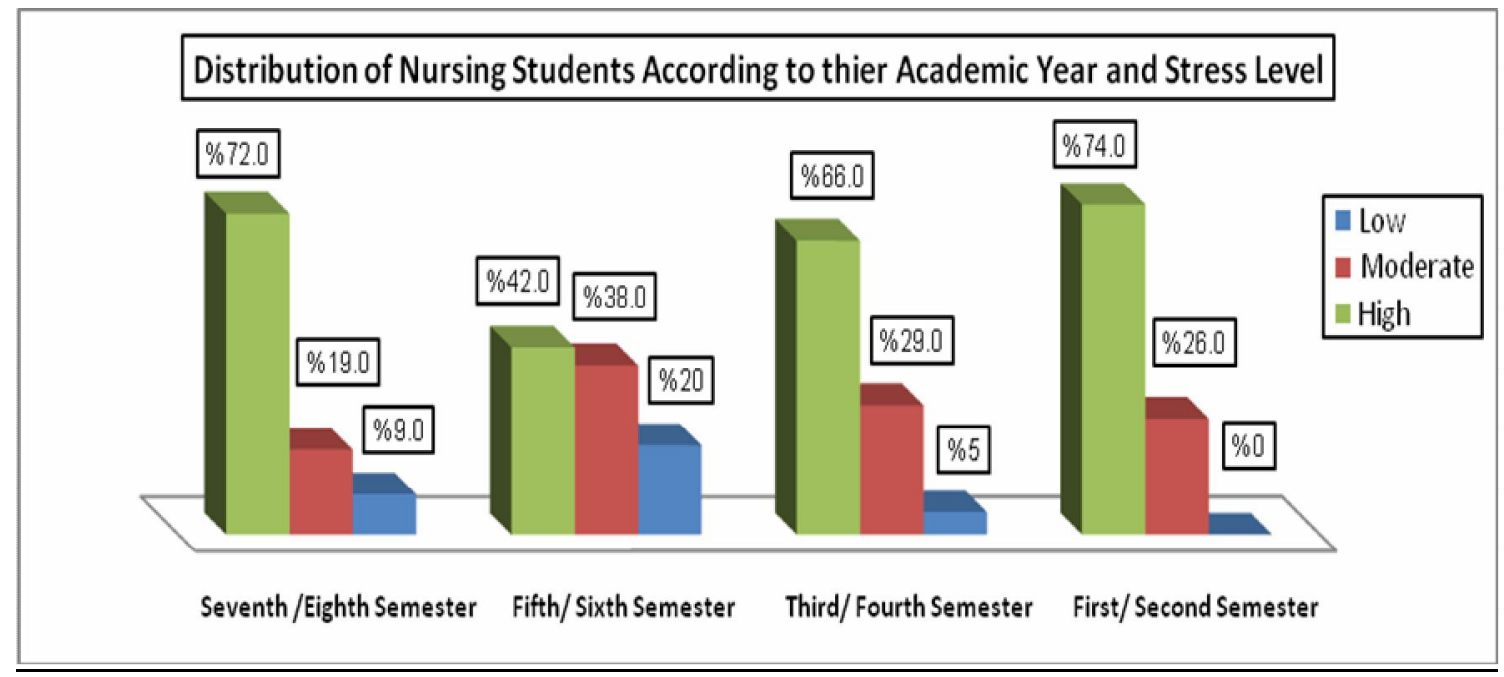

Figure (1): Distribution of nursing students according to their academic year and degree of stress 


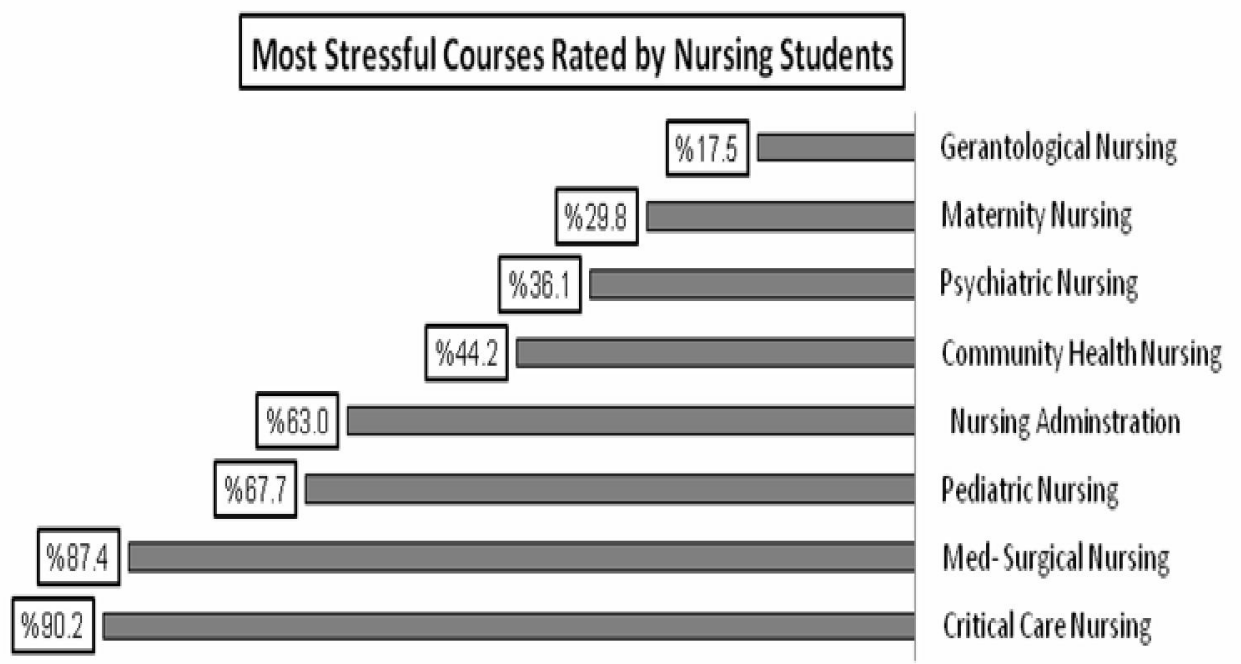

Figure (2): Distribution of the most stressful courses as rated by the nursing students

Table (5): Distribution of the nursing students according to their responses to stress exposure.

\begin{tabular}{|c|c|c|c|c|c|c|c|}
\hline \multirow{3}{*}{ Physio- Psycho- Social response } & \multicolumn{6}{|c|}{ Degree of response } & \multirow{3}{*}{$\begin{array}{c}\text { Mean score } \\
\text { X } \pm \text { SD }\end{array}$} \\
\hline & \multicolumn{2}{|c|}{ Mild } & \multicolumn{2}{|c|}{ Moderate } & \multicolumn{2}{|c|}{ Sever } & \\
\hline & No & $\%$ & No & $\%$ & No & $\%$ & \\
\hline - Physical symptoms & 294 & 73.5 & 92 & 23.0 & 14 & 3.5 & $1.41 \pm 0.72$ \\
\hline - Psychological symptoms & 317 & 79.3 & 67 & 16.7 & 16 & 4.0 & $1.82 \pm 0.67$ \\
\hline - Social- behavioral_symptoms & 252 & 63.0 & 122 & 30.5 & 26 & 6.5 & $1.25 \pm 0.71$ \\
\hline
\end{tabular}


Table (6): Distribution of the nursing students according to their coping strategies.

\begin{tabular}{||c|c|c|c|c|c|c|c||}
\hline \multirow{2}{*}{ Coping Strategies } & \multicolumn{6}{|c|}{ Frequency of use } & Mean score \\
\cline { 2 - 7 } & \multicolumn{2}{|c|}{ Never } & \multicolumn{2}{c|}{ Often } & \multicolumn{2}{c|}{ Always } & \multirow{2}{*}{ X SD } \\
\cline { 2 - 7 } & No & $\%$ & No & $\%$ & No & $\%$ & \\
\hline - Avoidance & 99 & 24.8 & 234 & 58.5 & 67 & 16.8 & $1.92 \pm 0.64$ \\
\hline - Problem solving & 13 & 3.3 & 126 & 31.5 & 261 & 65.3 & $2.62 \pm 0.54$ \\
\hline - Stay optimistic & 112 & 28.0 & 260 & 65.0 & 28 & 7.0 & $1.79 \pm 0.55$ \\
\hline - Transference & 41 & 10.3 & 148 & 37.0 & 211 & 52.8 & $2.42 \pm 0.67$ \\
\hline
\end{tabular}

Table (7): Distribution of the nursing students according to their perceived faculty support.

\begin{tabular}{|c|c|c|c|c|c|c|c|}
\hline \multirow{3}{*}{ PFS domains } & \multicolumn{6}{|c|}{ Perceived Faculty Support } & \multirow{3}{*}{$\begin{array}{c}\text { Mean score } \\
\mathrm{X} \pm \mathrm{SD}\end{array}$} \\
\hline & \multicolumn{2}{|c|}{ Low } & \multicolumn{2}{|c|}{ Moderate } & \multicolumn{2}{|c|}{ High } & \\
\hline & No & $\%$ & No & $\%$ & No & $\%$ & \\
\hline - Total PFS score & 15 & 3.7 & 326 & 81.5 & 59 & 14.8 & $2.11 \pm 0.42$ \\
\hline - Functional Support & 15 & 3.8 & 315 & 78.7 & 70 & 17.5 & $2.13 \pm 0.44$ \\
\hline - Psychological Support & 17 & 4.3 & 278 & 69.5 & 105 & 26.2 & $2.22 \pm 0.51$ \\
\hline
\end{tabular}

Table (8): Correlation between students' stress, coping strategies and faculty support.

\begin{tabular}{|c|c|c||}
\hline Statistical Test Pearson's r & $\begin{array}{c}\text { Correlation } \\
\text { Coefficient }\end{array}$ & Significance \\
\hline$-\quad$ Perceived faculty support & -0.635 & $0.007^{*}$ \\
\hline$-\quad$ Coping Strategies: Avoidance & -0.085 & 0.089 \\
\hline$-\quad$ Coping Strategies: Problem solving & -0.450 & $0.032^{*}$ \\
\hline$-\quad$ Coping Strategies: Stay optimistic & -0.100 & 0.371 \\
\hline$-\quad$ Coping Strategies: Transference & 0.023 & 0.648 \\
\hline
\end{tabular}

*significant at $\mathrm{P} \leq 0.05$ 
Table (9): Predictors of stress among the nursing students using binary logistic regression analysis (Enter method).

\begin{tabular}{|l|c|c|c|c||}
\hline Characteristics & B & S.E. & Wald & P \\
\hline Sex ( male/ female) & 0.214 & 0.437 & 0.240 & 0.624 \\
\hline Age ( less than 19 years/ more than 19 years) & -0.474 & 0.250 & 3.586 & 0.058 \\
\hline Marital status (married / not married) & -0.333 & 0.756 & 0.194 & 0.659 \\
\hline Residence place (urban/ rural) & 0.623 & 1.038 & 0.361 & 0.548 \\
\hline Live with parents (yes/no) & 0.790 & 0.696 & 1.289 & 0.256 \\
\hline Academic semester (junior / senior) & 0.762 & 0.336 & 5.129 & $0.024^{*}$ \\
\hline Health problems (yes/ no) & -0.760 & 0.509 & 2.230 & 0.135 \\
\hline Low social level ( yes/ no) & -0.080 & 0.556 & 0.021 & 0.886 \\
\hline Reason for joining faculty ( love nursing/ others) & 7.611 & 1.236 & 0.223 & $0.026^{*}$ \\
\hline Previous academic failure (yes/ no) & 2.213 & 1.013 & 4.769 & $0.029^{*}$ \\
\hline Last GPA (less than 2.7 points /more than 2.7 points) & -2.963 & 1.072 & 7.645 & $0.006^{*}$ \\
\hline Work beside education (yes/ no) & -1.346 & 0.662 & 4.137 & $0.042^{*}$ \\
\hline Regularity of attendance (regular/ irregular) & -0.532 & 0.858 & 0.385 & 0.535 \\
\hline Number of studying hours/ day ( less than 3 hours/ more & 0.328 & 0.151 & 4.743 & $0.029^{*}$ \\
\hline Number of sleeping hours/day (less than 5 hours/ more) & 0.364 & 0.187 & 3.774 & $0.052^{*}$ \\
\hline Practicing extracurricular activities ( yes/ no) & -0.724 & 0.362 & 3.997 & $0.046^{*}$ \\
\hline Satisfaction with nursing career (yes/ no) & 1.281 & 0.550 & 5.425 & $0.020^{*}$ \\
\hline Family satisfaction with nursing career (yes/ no) & 0.734 & 1.195 & 0.377 & 0.539 \\
\hline Faculty support (yes/ no) & -0.252 & 0.774 & 0.106 & $0.039^{*}$ \\
\hline \hline
\end{tabular}




\section{References}

1. Watson R, Deary I, Thompson D. A study of stress and burn out in nursing students in Hong Kong. International Journal of Nursing Studies 2008; 45 (10): $1534-42$.

2. Yucha C, Kowalski S, Cross C. Student Stress and Academic Performance: Home Hospital Program. Journal of Nursing Education 2009; 48 (11): 631 7.

3. Gibbons C, Dempster M, Moutray M. Index of Sources of Stress in Nursing Students: a Confirmatory Factor Analysis. Journal of Advanced Nursing 2009; 65 (5) 1095-102.

4. Walton R. A Comparison of Perceived Stress Levels and Coping Styles of Junior and Senior Students in Nursing and Social Work Programs. PhD thesis, College of Graduate Studies, Marshall University, West Virginia, 2002.

5. Bayoumi M, El Basuny M, Mofereh A, Ali M, Hussein A. Evaluating Nursing Students' Anxiety and Depression during Initial Clinical Experience. International Journal of Psychology and Behavioural Sciences 2012; 2 (6): 277 81.

6. Watson R, Gardiner E, Hogston R, Gibson H, Stimpson A, Wrate R, Deary I. A Longitudinal Study of Stress and Psychological Distress in Nurses and Nursing Students. Journal of Clinical Nursing 2009; 18 (2): 270- 8.

7. Shaban I, Khater W, Akhu-Zaheya L. Undergraduate Nursing Students' Stress Sources and Coping Behaviours during Their Initial Period of Clinical Training: A Jordanian Perspectives. Nursing Education in Practice 2012; 12: 204-9.

8. Gibbons C, Dempster M, Moutray M. Stress and Eustress in Nursing Students.
Journal of Advanced Nursing 2008; 61 (3) 282-90.

9. Mohamed S. Stress, Strain and Coping Mechanisms: An Experimental Study of Fresh College Students. Academy of Educational Leadership Journal 2012; 16 (1):19-31.

10. Ming Y, Wang M. Stress Coping Styles of Students at Universities and Colleges of Technology. The Journal of American Academy of Business 2010; 15 (2):313-8.

11. Ward M. Student Nurses Perceptions of Health Promotion. Nursing Standard 2011; 11(24):34-40.

12. El-Gilany A, El-Wehady A, El-Wasify M. Updating and Validation of the Socioeconomic Status Scale for Health Research in Egypt. Eastern Mediterranean Health Journal 2012; 18 (9): 962-8.

13. Jones M, Johnston D. The Derivation of a Brief Student Nurses Stress Index. Work Stress 1999;13 (2):162-81.

14. Sheu S, Lin H, Hwang S. Perceived Stress and Physical Psycho- Social Status of Nursing Students during their Initial Period of Clinical Practice: The Effect of Coping Behaviors. International Journal of Nursing Studies 2002; 39(2): 165-75.

15. Shelton E. Faculty Support and Student Retention. Journal of Nursing Education 2003; 42 (2): 68-76.

16. Gurbinder K, Hamidah H, Blackman I, Wotton K, Belan I. Perceived Stress Related to Nursing Education and its Influence on Nursing Students' Academic and Clinical Performance. Med \& Health 2011, 6(2):86-97.

17. Singh C, Sharma S, Kumar R. Level of Stress and Coping Strategies Used by Nursing Interns. Nursing and Midwifery Research Journal 2011; 7(5):152-60. 
18. Mohamed B, Ahmed E. Perception of Nursing Students towards Clinical Stressors in the Faculty of Applied Medical Science: Al Jouf UniversitySaudi Arabia. Journal of American Science 2012; 8 (12): 608-17.

19. Jensen A. Perceived Work Stress in Nursing Students during Clinical Training: The Role of Coping Process and Social Support. PhD thesis, Faculty of Pacific Graduate School of Psychology, California University, California, 2007.

20. Misra R, Mckean M. College Students' Academic Stress and Its Relation to their Anxiety, Time Management and Leisure Satisfaction. American Journal of Health Studies 2011; 16 (1): 41-51.

21. Edwards D, Burnard P, Bennett K, Hebden U. A Longitudinal Study of Stress and Self Esteem in Student Nurses. Nurse Education Today 2010; 30: 78-84.

22. Kit C. Perceived Stress and Coping Strategies of Baccalaureate Nursing Students in Clinical Training. Master thesis, Faculty of Nursing, Hong Kong University, Hong Kong, 2006.

23. Burnard P, Thiabah H, Hay D, Edwards D. A Descriptive Study of Bruneian Student Nurses' Perception of Stress. Nurse Education Today 2007; 27: 80818.

24. Jabien L .Stress, Stressors and Stress Responses of Nurses in a Government Nursing School. Health Science Journal 2013; 7 (4): 424-35.

25. Chan K, So K, Fong Y. Hong Kong Baccalaureate Nursing Students' Stress and their Coping Strategies in Clinical
Practice. Journal of Professional Nursing 2003; 25 (5): 307-13.

26. Burnard P, Edwards D, Bennett K, Thiabah H, Tothova V, Baldacchino D etal. A comparative Longitudinal Study of Stress in Student Nurses in Five Countries: Albania, Brunei, The Czech Republic, Malta and Wales. Nursing Today 2008; 28: 134-35.

27. Mohamed M. Psychosocial Stress and Coping Patterns among Students in the Faculty of Nursing Ain Shams University. The New Egyptian Journal of Medicine 2008; 38 (4) supplement 1:46-58.

28. Latrice D. Student Nurse Stress and Perceived Faculty Support: A Triangulation Study with Foreign Born Baccalaureate Nursing Students. PhD thesis, College of Nursing, Texas University, USA, 2008.

29. El Sayed T, Mohamed A, Ismail W, Mohamed N. Effect of Faculty Support and Nursing Students' Self Efficacy and Affective Commitment on their Academic Achievement. Life Science Journal 2013; 10(3):2707-16.

30. Amr M, El Gilany A, El Moafee H, Salama L, Jimenez C. Stress among Mansoura (Egypt) Baccalaureate Nursing Students. Pan African Medical Journal 2011; 26 (8):1-8.

31. Sharma S, Kaur A. Factors Associated with Stress among Nursing and Midwifery. Research Journal 2011; 7(1):12-21.

32. El Gilany A, Amr M, Hammad S. Perceived Stress among Medical Students in Egypt and Saudi Arabia: Effect of Socio demographic Factors. Ann Saudi Medical 2008; 28 (6):442-8. 